\title{
Power Quality and Air Emission Tests in a Micro Gas Turbine Cogeneration Plant
}

\author{
J.C. Bruno ${ }^{1}$, Ll. Massagués ${ }^{2}$ and A. Coronas ${ }^{1}$ \\ ${ }^{1}$ CREVER - Universitat Rovira i Virgili \\ Autovía de Salou, s/n, 43006 Tarragona (Spain) \\ phone:+34 977 540205, fax:+34 977 542272, \\ e-mail: acoronas@crever.urv.es \\ ${ }^{2}$ ETSE - Universitat Rovira i Virgili \\ Dept. d'Enginyeria Electrònica, Elèctrica i Automàtica \\ Avda. Països Catalans, s/n, 43007 Tarragona (Spain)
}

\begin{abstract}
Distributed generation is an attractive way of producing energy, minimising transport losses and enhancing energy efficiency. Micro gas turbines in distributed generation systems add other advantages such as low emissions and fuel flexibility.

The objective of this paper is to present the experimental data of a $28 \mathrm{~kW}$ microturbine and a hot water waste-heat boiler at the testing facilities of CREVER in Tarragona. The purpose of this project is to determine their technical and economical viability, and their performance. The electrical efficiency measured is within the specifications provided by the manufacturer and decreases considerably with the power output. Air emissions are very low at full load and do not increase appreciably until the load is reduced below $60-70 \%$ of the full load.

The results confirm that the power quality and air emissions in microturbines comply with the existing standards and that they are very competitive in comparison with other technologies in these aspects. Thus considerable market development is expected in the coming years although more research and development efforts will be needed.
\end{abstract}

\section{Key words}

Micro gas turbine, power quality, air emissions, distributed generation, co/trigeneration

\section{Introduction}

The present situation of the energy market has highlighted the need to increase energy efficiency and promote the deployment of environmentally sustainable and economically efficient distributed power generation technologies. One of these technologies is based on micro gas turbines in conjunction with waste-heat driven cooling and heating technologies in order to increase overall efficiency. Distributed generation is an attractive way of producing energy in the point of use, minimising transport losses and enhancing energy efficiency. The use of micro gas turbines in distributed generation systems add other advantages such as low emissions and fuel flexibility [1].

Increasing concern with climate change and environmental pollution will increase pressure to introduce energy-efficient technologies as the new micro gas turbines that are beginning to enter the commercial market in Spain [2].

The concept of DG includes the concept of CHP (Combined Heat and Power) initially developed for industrial applications. Nowadays, however, the application range has been extended to cover the tertiary sector. Several Building Cooling Heating and Power (BCHP) technologies have been proposed. One of these is based on on-site power generation using micro gas turbines driven by natural gas in conjunction with wasteheat driven cooling and heating technologies. In the Mediterranean area the major concern is space cooling rather than heating. In this situation, absorption chilling is a key technology in BCHP because it makes it possible to transform waste heat into cooling. At the same time it can reduce the building's electrical requirements, increase the gas turbine capacity by inlet air cooling and provide the necessary space cooling in summer. Single-effect absorption chillers can operate in combination with microturbines using conventional heat recovery systems. However, the low performance of these chillers does not make this combination very competitive. Directly coupling microturbine exhaust gases to the air supply of a direct-fired, double-effect chiller appears to be a much better option [3]. This technology is known as co-fired microturbine/absorption systems.

Nowadays there are some demonstration projects with different scopes to assess the performance of micro gas turbines: for example, the Microturbine Field Test Program conducted by EPRI (Electric Power Research Institute), by APEP in California, ORNL in Tennessee [4] and CEEE in Maryland, all of them in the USA; the European Project OMES (Optimised Microturbine Energy Systems) base on the microturbine of Turbec [5], other several tests with different microturbines run by N.V. Nederlandse Gasunie in Holland and others in Asia, 
by Osaka Gas Co. and Tokyo Gas Co. in Japan or the National University of Singapore among others.

The objective of this paper is to present the experimental data of a $28 \mathrm{~kW}$ microturbine and a hot water waste-heat boiler at the testing facilities of CREVER in Tarragona (Fig. 1). The results summarised here will focus mainly on their electrical and air emission performance when the microturbine operates in stand-alone mode and connected to the grid.

The purpose of this project is to determine whether these plants are technically and economically viable in the environmental and economic context of Tarragona and how they perform in terms of heat, cooling and power production, gas emissions and electrical power quality [6, 7].

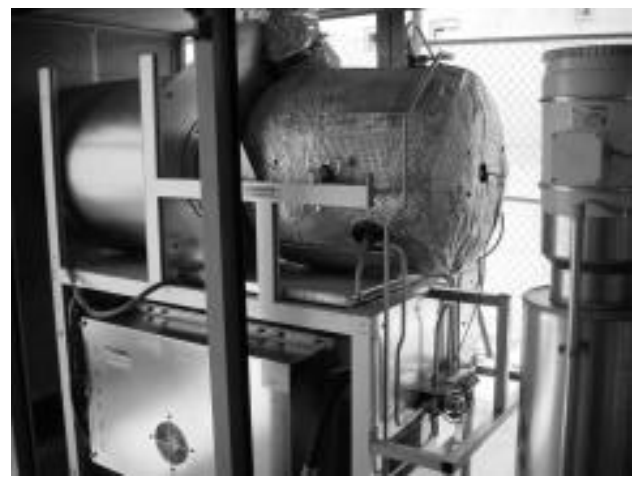

Fig. 1. View of the microturbine tested and its Digital Power Controller (DPC)

\section{State of the art of micro gas turbines}

Micro gas turbines are turbo-alternators of up to $200 \mathrm{~kW}$, which consist of a centrifugal compressor, a radial turbine and an alternator rotor operating as a Brayton cycle. Their main feature is that a high speed generator is directly coupled to the turbine rotor and that they use power electronics instead of a gearbox and a conventional generator [1,2]. Other mini gas turbines of greater electrical capacities will not be considered in this study.

When biomass is used, where the average power output is in the order of magnitude of some hundred $\mathrm{kW}$, micro turbines could be the process of choice. Together with their capacity to burn fuels with different calorific values, they seem to be promising CHP-systems for biomass.

Microturbines usually use a single shaft. This configuration has lower production costs than the double shaft configuration and the generator can also be mounted opposite the gas exhaust, so the gases leave the turbine with less pressure loss, which increases the net power and reduces the fuel consumption. Another way to decrease the fuel consumption is to use regenerators to preheat the inlet air. This doubles the electricity efficiency, but reduces the heat that can be recovered from the exhaust gas, so in some microturbines the regenerator can be completely or partially bypassed if required. A simple cycle configuration that is, a non regenerative cycle is a valid option when the main purpose of the plant is to produce waste heat at very high temperature to obtain greater overall efficiency rather than greater electrical efficiency.

Microturbine turbomachinery is based on single-stage radial flow compressors and turbines. Radial flow turbomachinery handles the small volumetric flows with reasonably high component efficiency. The economic cost is also lower than that of axial components. The main drawback of radial compressors and turbines is that they are less efficient, so axial turbines are preferred for gas turbines of higher capacities.

All the above features mean that microturbines have some advantages over other competing technologies such as natural gas reciprocating engines. These advantages are:

- They are lightweight and very compact systems.

- They produce low noise level and are vibration free.

- Their exhaust gas emissions are lower than those of competing technologies with the only exception of fuel cells.

- Like other gas turbines, the heat recovery system is less complex than that of engines.

- They require less maintenance, specially the oil free microturbines.

Table 1. Current manufacturers of micro gas turbines (less than $200 \mathrm{~kW}$ )

\begin{tabular}{|l|l|}
\hline Manufacturer & Range of models \\
\hline Capstone Turbine Corporation & $\begin{array}{l}30 \mathrm{~kW}, 60 \mathrm{~kW} \text { (next } \\
200 \mathrm{~kW})\end{array}$ \\
\hline Elliot Energy Systems Inc & $80 \mathrm{~kW}$ \\
\hline Turbec AB & $100 \mathrm{~kW}$ \\
\hline Bowman Power Ltd & $50 \mathrm{~kW}, 80 \mathrm{~kW}$ \\
\hline Ingersoll-Rand Energy Systems & $70 \mathrm{~kW}$ \\
\hline
\end{tabular}

To deal with the greater use of microturbines, in the coming years it will be necessary to specify standards for the low voltage (distribution) grid interconnection of power distributed systems based on the new technology of micro gas turbines. The issues to be analysed are:

- The quality of the power supplied

- Specific grid protection measures for distributed generation with micro gas turbines.

- The effect of distributed generation on the grid

- Management of distributed generation systems interconnected to the grid

\section{Description of the test facilities}

\section{A. Cogeneration plant}

The cogeneration plant test facility consists of:

- A regenerative Capstone microturbine of $28 \mathrm{~kW}$ using low pressure natural gas. This unit can be converted to a high pressure unit so it can be fuelled by propane or biogas. 
- A heat exchanger to produce hot water up to $90^{\circ} \mathrm{C}$.

- A lead-acid battery package and controller so that it can be operated as a stand-alone system but it can also be connected in parallel to the grid.

- A cooling tower to dissipate and simulate heat loads at different return temperatures.

This microturbine is an oil-free system that uses air bearings. Its permanent-magnet high-speed 2-pole generator is also cooled with air. The generator is directly coupled to the turbine and compressor shaft without a gearbox.

For a microturbine stand alone system, the batteries are charged during the normal microturbine operation if necessary or they are used to match transient high loads.

The inlet air is used not only as combustion air but also to cool the micro turbine electronics.

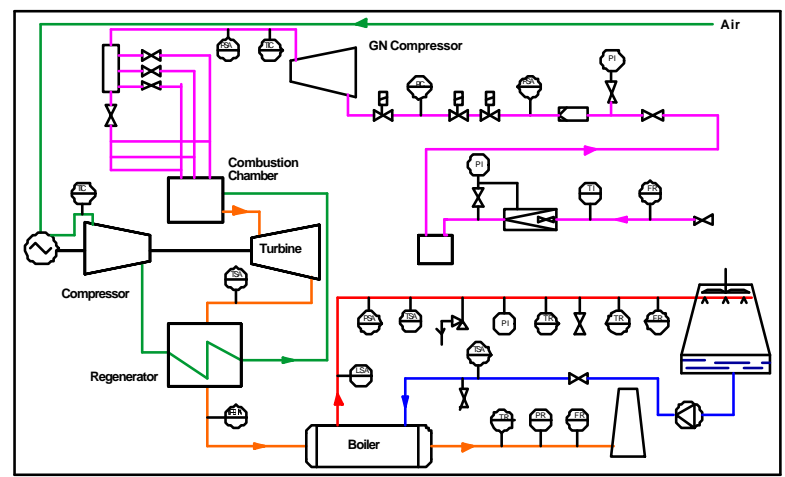

Fig. 2. Diagram of the microturbine experimental test facility

\section{B. Electrical System}

The high-speed generator design uses a permanent magnet alternator, and requires that the high frequency AC output (1600 Hz at full load) be converted to $50 \mathrm{~Hz}$. This power conditioning involves rectifying high frequency $\mathrm{AC}$ to $\mathrm{DC}$, and then inverting the $\mathrm{DC}$ to $50 \mathrm{~Hz}$ AC. To start-up the turbine the generator acts as a motor, turning the turbo-compressor shaft until sufficient speed is reached to start the combustor.

The microturbine in stand-alone mode was set to provide 3-phase $400 \mathrm{VAC}$ although it can supply up to $480 \mathrm{VAC}$ and it automatically determines the power demand by current draw of the load. To modulate the demand so that the turbine can be tested as a stand-alone system we use a bank load of resistive $(2 \times 3.5 \mathrm{~kW}, 8.7 \mathrm{~kW}, 11.3 \mathrm{~kW})$ and inductive $(3 \times 1.4 \mathrm{~kW})$ loads.

In grid-connected mode, the micro turbine automatically matches the grid frequency and voltage.

The micro turbine incorporates many of the grid and system protection features required for the interconnection to the grid, including the following builtin relay functions:

- Under/over voltage

- Fast under/fast over voltage

- Over/under frequency

- Rate of change of frequency

\section{Measuring instruments and data logging}

A PC-based Data Acquisition System (DAS) and other measurement equipment for process, environmental and electric parameters were installed to determine the performance of the system. The DAS is a Siemens PCS7 compact system. The field measurements are obtained through I/O cards ET200M connected to the CPU 416DP2 using Profibus technology. These measurements include the process variables associated with the natural gas consumed, ambient conditions, hot water and exhaust gas. The micro turbine internal parameters: rotation speed, Turbine Exit Temperature (TET), etc. are monitored via the software built into the micro turbine.

A Schneider Electric CM 4000 electric grid analyser is used to monitor the electric energy produced using the PC software SMS-121 for system configuration, monitoring and data logging.

A flue gas analyser Testo $350 \mathrm{XL}$ is used to monitor mainly the oxygen excess, carbon monoxide (CO), nitrogen oxides (NO, $\left.\mathrm{NO}_{2}, \mathrm{NO}_{\mathrm{x}}\right)$ and unburned hydrocarbons.

\section{Results}

\section{A. Electrical efficiency}

The electrical efficiency measured is within the specifications provided by the manufacturer and decreases considerably with the power output. So it seems advisable to work at the highest load possible most of the time. This efficiency already includes the internal electricity consumption for the electric natural gas compressor and other internal loads.

Figure 3 shows the thermal efficiency, defined as the useful heat provided by the heat recovery boiler divided by the consumption of fuel, and also the global efficiency considering heat and electricity as useful products of the same quality. The results shown in this figure were taken at an ambient temperature between 25 and $30^{\circ} \mathrm{C}$. As expected, at colder temperatures the efficiencies increase significantly.

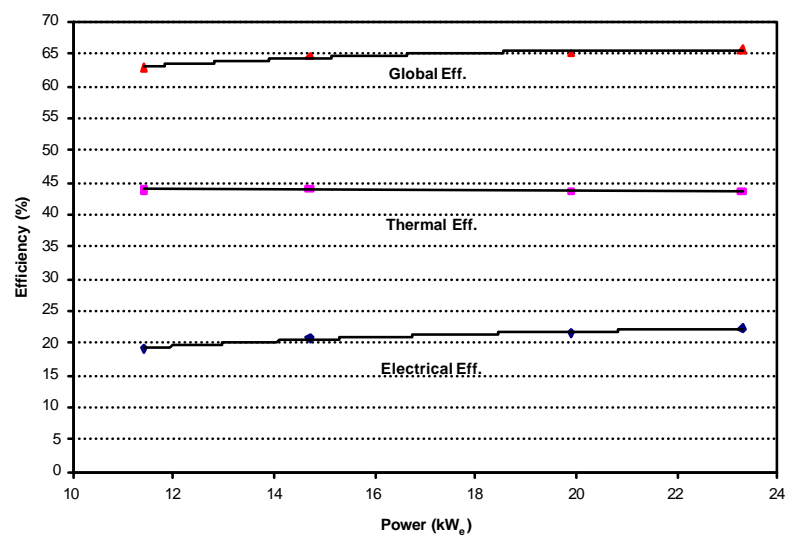

Fig. 3. Micro turbine efficiency at ambient temperatures between $25-30^{\circ} \mathrm{C}$ 


\section{B. Power Quality}

Figures 4 and 5 show the voltage and current waveform at $26.9 \mathrm{~kW}$. There is a small distortion in both wave forms mainly due to the third harmonic. The same is true of non-linear (inductive) loads. At lower power loads the waveform presents a higher, but not very significant, distortion. Figure 6 represents the harmonic spectrum for voltage phase $1-\mathrm{N}$ at $26.9 \mathrm{~kW}$. The most significant harmonic is number 3 but in all cases it is higher than the maximum values specified by the international standards. The results for the other phases are very similar.

The power generated complies with the voltage distortion limits indicated in the standards IEEE 519-1992 (IEEE Recommended Practices and Requirements for Harmonic Control in Electrical Power Systems) [8] and CENELEC EN50160-1999 (Voltage Characteristics of Electricity Supplied by Public Distribution Systems). Figures 7 and 8 compare the voltage and current harmonic spectrum with the IEEE 519 standard for $20 \mathrm{~kW}$.

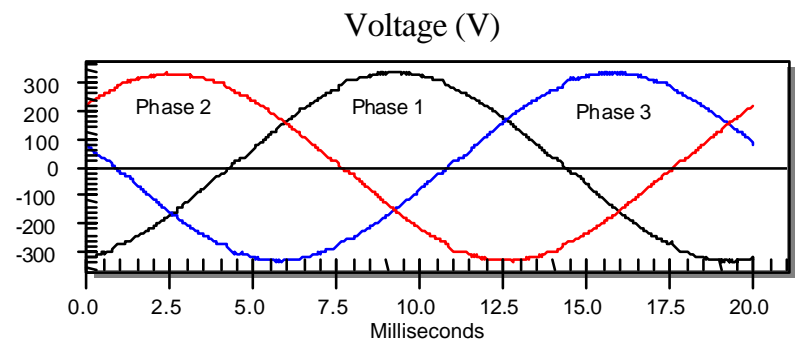

Fig. 4. Voltage wave forms at $26.9 \mathrm{~kW}$

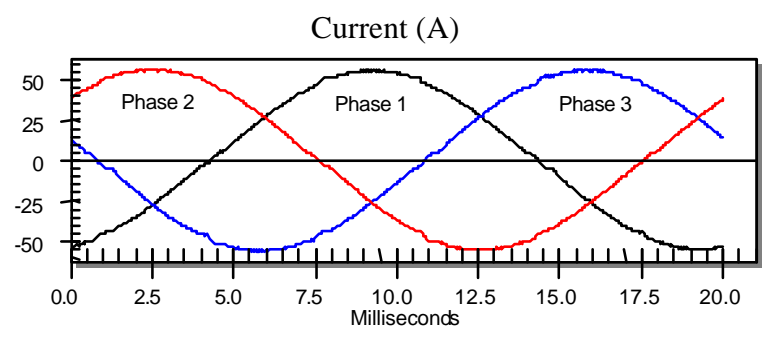

Fig. 5. Current waveforms at $26.9 \mathrm{~kW}$

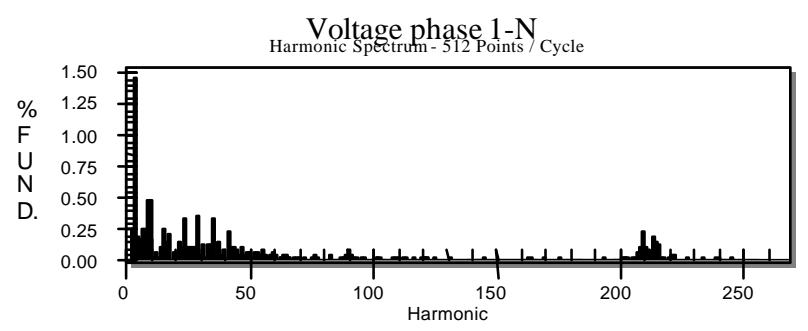

Fig. 6. Harmonic spectrum at $26.9 \mathrm{~kW}$

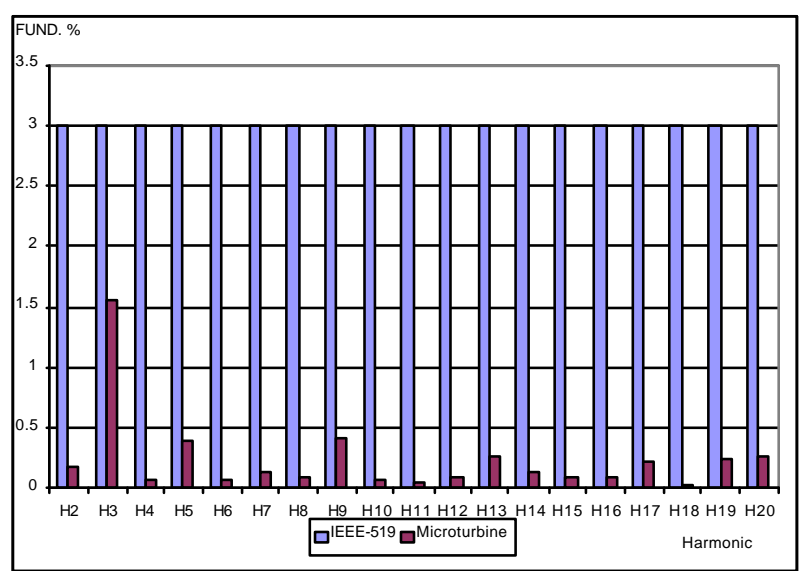

Fig. 7. Comparison of the voltage harmonic spectrum at $20 \mathrm{~kW}$

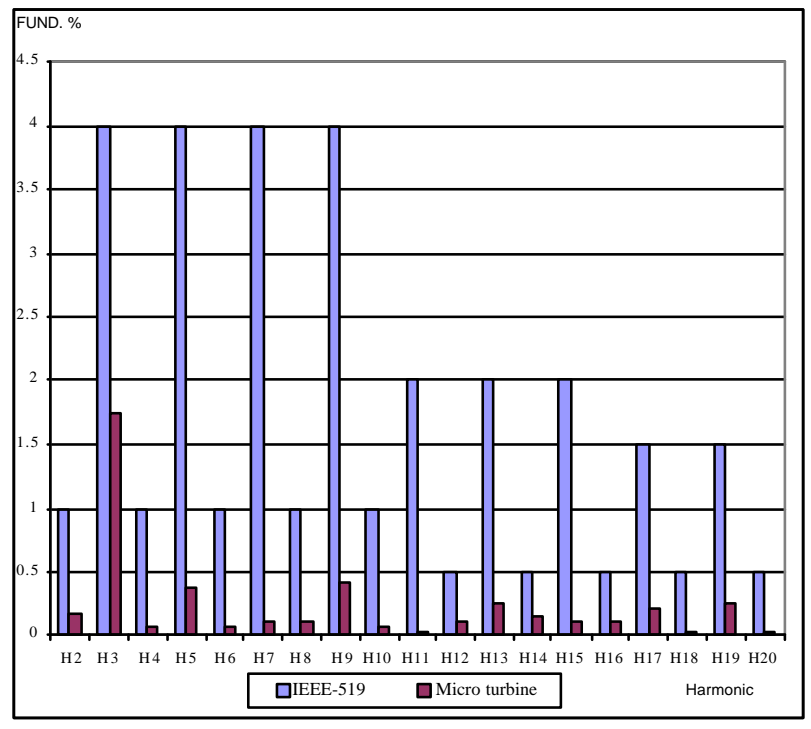

Fig. 8. Comparison of the current harmonic spectrum at $20 \mathrm{~kW}$

\section{Air Emissions}

The micro turbine uses a great excess of combustion air. Figure 9 shows the oxygen concentration at the micro turbine exhaust gas.

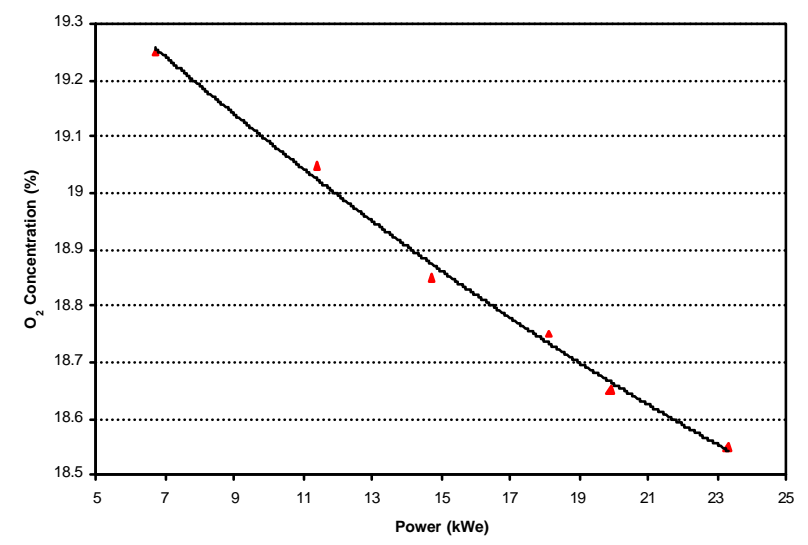

Fig. 9. Percentage of oxygen concentration at different power loads 
Air emissions are very low at full load and do not increase appreciably until the load is reduced below $60-$ $70 \%$ of the full load. The primary pollutants from microturbines are oxides of nitrogen $\left(\mathrm{NO}_{\mathrm{x}}\right)$, carbon monoxide $(\mathrm{CO})$ and unburned hydrocarbons.

When there is insufficient residence time at high temperature, the result is $\mathrm{CO}$ emissions, which are also heavily dependent on operating load (Fig. 5).

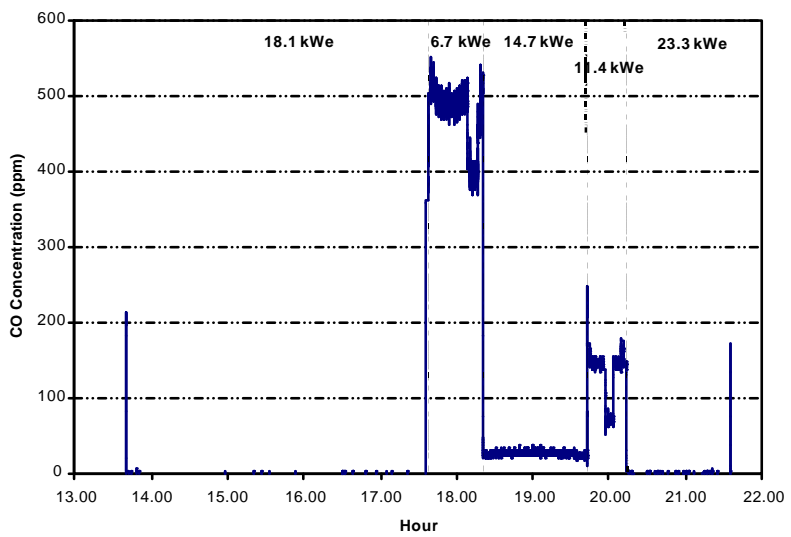

Fig. 10. CO emissions at different power loads

The pollutant referred to as $\mathrm{NO}_{\mathrm{x}}$ is a mixture of variable composition of mostly $\mathrm{NO}$ and $\mathrm{NO}_{2}$. . The microturbine uses a lean premixed combustor technology that considerably reduces $\mathrm{NO}_{\mathrm{x}}$ formation. Figure 11 shows the $\mathrm{NO}_{2}$ concentration for $23.3 \mathrm{~kW}$. As can be seen, it is only significant during start-up and low during normal operation. The measured NO concentration is even lower than that of $\mathrm{NO}_{2}$.

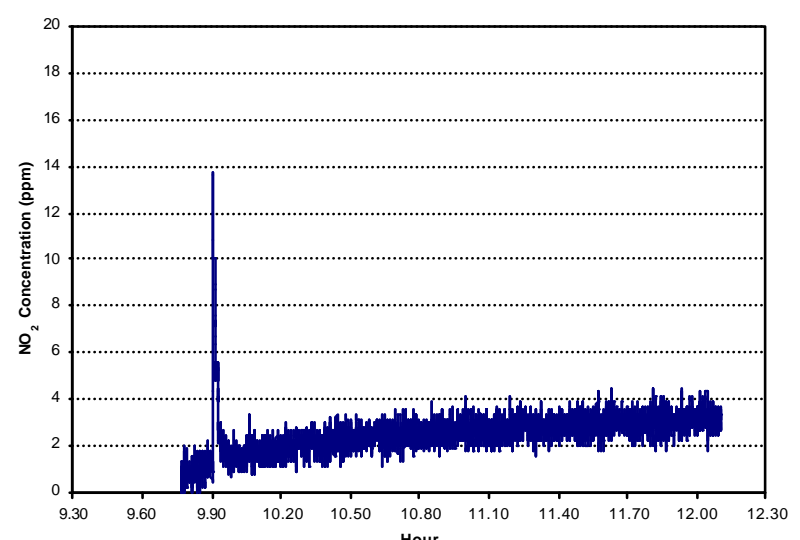

Fig. 11. $\mathrm{NO}_{2}$ emissions at $23.3 \mathrm{~kW}$

\section{Conclusions}

The results confirm that the power quality in microturbines complies with the existing international standards on harmonic distortion. The tested microturbine achieve the objective of low emissions at full load. Emissions are higher at low load.
In comparison with others, this technology is highly competitive in terms of power quality and air emissions. Thus it is expected that there will be considerable market development in the coming years if the economic context is appropriate. More research and development will be needed, however, specially with grid interconnection issues and the use of low calorific value fuels obtained from waste materials.

\section{Acknowledgement}

The authors would like to acknowledge the partial funding of this project by Gas Natural SDG, S.A. and the Department of Energy, Industry and Commerce of the Generalitat de Catalunya (the Catalan government).

\section{References}

[1] B. Peters, K. Dielmann, "Capstone Microturbines: Experiences with Different Gaseous and Liquid Fuels". Workshop on Energy Efficiency \& Emissions Reduction with Micro Gas Turbines - Technology and Operating Experience, October, $22^{\text {nd }}$, Tarragona, 2002.

[2] J.C. Bruno, A. Hinestrosa, A. Coronas, "Estado Actual de la Tecnología de las Microturbinas de Gas". Energía. No. 163, 42-47, 2002.

[3] Sweetser, R., Devault, R., Foley, G. "Absorption Technologies for Buildings: Cooling, Heating and Power (BCHP) Systems". HPAC Heating/Piping/Air Conditioning Engineering, 51-56, July 2000.

[4] P.D. Fairchild, S.D. Labinov, A. Zaltash, B.Rizy. "Experimental and theoretical study of microturbinebased BCHP system", ASME International Congress and Exposition, New York, 2001.

[5] Pedersen, A.H., "Microturbine Energy Systems. Description of an EU project (OMES) and gained experiences with prototypes". International Gas Research Conference (IGRC), Amsterdam, novembre 2001.

[6] J.C.Bruno, Ll. Massagués, A. Coronas, "On-Site Energy Generation Potential Based on Micro Gas Turbines for Commercial Buildings in Mediterranean-Climate Areas", Proc. $2^{\text {nd }}$ International Conference IEECB, Nice (France), may, 2002.

[7] J. C. Bruno and A. Coronas, "Monitorización y Análisis Energético de un Sistema de Cogeneración Basado en una Microturbina de gas de $28 \mathrm{kWe}$. Proc. XV Congreso Nacional de Ingeniería Mecánica, 10-13 Diciembre, Cádiz, 2002.

[8] IEEE Std. 519-1992, IEEE Recommended Practices and Requirements for Harmonic Control in Electrical Power Systems. IEEE, New York, 1993. 